Acta Botanica Brasilica - 35(4): 714-718. October-December 2021. doi: 10.1590/0102-33062020abb0462

\title{
Seed predation by macaws favors fruits with less seeds and thicker endocarps in the palm Attalea phalerata
}

\author{
Camila S. Barros ${ }^{1 *}$ (i) and Alexandra S. Pires ${ }^{1,2}$ (D)
}

Received: October 27, 2020

Accepted: June 28, 2021

\begin{abstract}
When foraging on a specific range of fruits or seeds, animals can represent a natural selection force, affecting plant population realized fecundity. Most studies have focused on characteristics of dispersed seeds, but the higher predation of seeds of specific size or shape is also an important force that influences the populations' realized fecundity and can help to understand patterns of plants genetic variability. In the Brazilian Pantanal, we investigated the predation of Acuri (Attalea phalerata) palm fruits by macaws, whose seeds go intact through tapirs digestive tract and then are deposited on latrines, where they are often consumed by seed predators. We found 251 fruits, containing between 1 and 5 seeds per fruit; 170 were intact and 81 had been partially damaged by macaws, mostly those containing 3 or 4 seeds per fruit and with thin endocarps. We argue that the higher consumption of fruits with these traits reflects a trade-off in the energy spent by macaws to open the fruits and the energy provided by them. Higher predation on 3-4 seeded fruits favors the selection of 1-2 seeded fruits, revealing a selection force opposed to the one exerted by bruchids and small rodents, which favors multi-seeded palm fruits.
\end{abstract}

Keywords: Anodorhynchus, Arecaceae, Brazil, macaws, multiple seeded fruits, palms, Pantanal, seed predation

Frugivorous and seed predator animals play important roles in ecological processes involving plant populations, affecting individuals' reproductive success and selection for particular traits. Frugivorous and seed eating animals may choose which fruiting species to feed on, which plant individual to forage on and which fruits among those available in the tree they will consume. These choices may represent natural selection driving forces, when animals show preference for a specific size or shape of fruits or seeds, since they may influence plants' realized fecundity (Jordano 1995).

The acuri palm (Attalea phalerata) is an important food resource at Neotropical forests, as its fruits are largely

1 Programa de Pós-Graduação em Ecologia, Universidade Federal do Rio de Janeiro, 21941-971, Rio de Janeiro, RJ, Brazil 2 Departamento de Ciências Ambientais, Universidade Federal Rural do Rio de Janeiro, 23890-000, Seropédica, RJ, Brazil

* Corresponding author: camilasdebarros@gmail.com 
consumed by rodents, wild pigs, tapirs, rheas and raptors (Quiroga-Castro \& Róldan 2001; Galetti \& Guimarães 2004). Some of these species act as effective dispersers, as for example, scatter-hoarding rodents, which promote higher germination success by protecting seeds from bruchid predation through seed burial (Dracxler \& Forget 2017). A (Tapirus terrestris), which moves seeds over large distances before defecating them (Fragoso et al. 2003; Tobler et al. 2010). This species ingests whole palm fruits and during the rumination process, pulp is stripped off, with only the exocarp and mesocarp being consumed while the endocarp is regurgitated or defecated intact in latrines. Tapir latrines frequently present a high number of palm fruits with intact seeds inside the endocarps (Yamashita 1997; Quiroga-Castro \& Roldán 2001), which are usually able to germinate after passing through digestive tract of tapirs (Capace et al. 2013). In Pantanal and Amazonia, latrines are usually at areas susceptible to seasonal floods, which may prevent seed germination (Quiroga-Castro \& Roldán 2001). However, the flood itself may promote seed dispersal to areas more suitable for germination, as it happens for other plant species (Fragoso 1997).

In the Brazilian Pantanal, besides small rodents (Camilo Alves \& Mourão 2010) and bruchid beetles (Quiroga-Castro \& Roldán 2001), the Hyacinth macaw Anodorhynchus hyacinthinus predates A. phalerata seeds (Guedes \& Harper 1995). Palm seeds are an essential food source for macaws, especially for Anodorhynchus species that live preferentially in areas where this plant is abundant (Brandt \& Machado 1990; Yamashita \& Valle 1993; Yamashita 1987; 1997). Although macaws are able to remove fruits directly from palm trees (Brandt \& Machado 1990), they frequently obtain seeds from latrines and also cattle ruminations, which were suggested as evidence of their relationship with the extinct megafauna (Yamashita 1997; Pires et al. 2014). In fact, the habit of Anodorhynchus macaws of following cattle and also tapir herds is thought to be a behaviour derived from adaptations to follow the now extinct megaherbivores, which disappeared around 10,000 years ago (Yamashita 1997).

Macaws consume seeds by opening the endocarp of fruits acting, thus, mostly as seed predators. The typical transverse cut made by macaws at the endocarp to extract the seeds allows the inference of fruits consumed by these birds (Yamashita 1987; 1997). Macaws can damage a large amount of palm fruits (Brandt \& Machado 1990), affecting the reproductive success of the plant species and possibly acting as important drivers of the evolution of fruit traits in acuri palms. Here we hypothesized that macaws select larger fruits which contain more seeds and could be easier to open due to their thinner endocarps.

In October 2006 fruits of Attalea phalerata (Arecaceae), either intact or consumed by macaws, were collected in six tapir latrines found around saline lakes at Fazenda Rio Negro, Pantanal da Nhecolândia, Mato Grosso do Sul. Attalea phalerata fruits are ellipsoid-oblong (Fig. 1), 6-11 $\mathrm{cm}$ long and 3-5 $\mathrm{cm}$ in diameter, and can harbour from one to five seeds (Galeano et al. 1995). We have no reason to believe that the distribution of fruit sizes consumed by tapirs is distinct from the distribution in the plant population. At this study site, the most abundant macaw is Anodorhynchus hyacinthinus, while other macaws are rarely recorded (Machado et al. 2009).

For each fruit collected (including both consumed and intact) we measured the largest diameter and endocarp thickness with a digital calliper and also counted the number of seeds. To calculate the mean endocarp thickness, four measures were taken from each endocarp (Fig. 1B). For diameter we took three distinct measures in the same fruit and considered only the largest value (Fig. 1C; Fig. S1 in
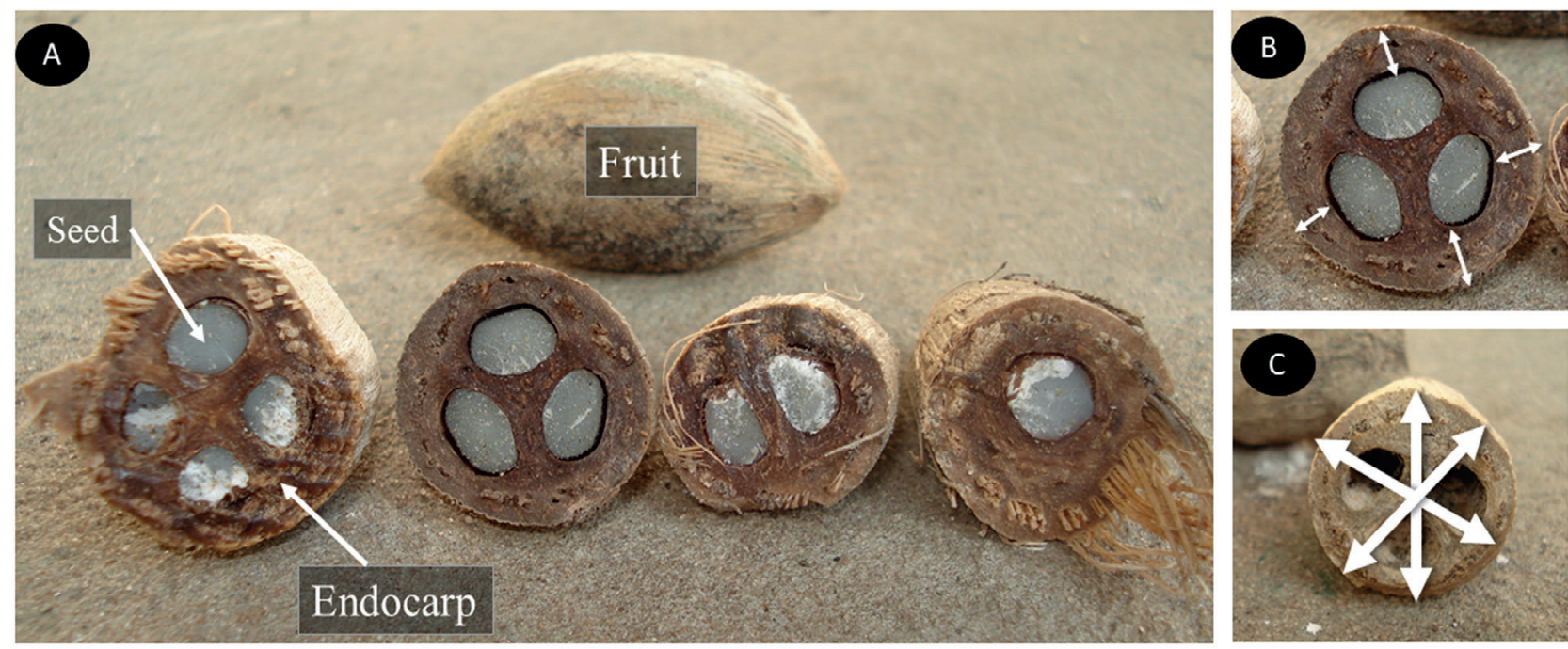

Figure 1. Samples of Attalea phalerata fruits. (A) Indication on what we called a whole fruit, seeds and endocarp. (B) Arrows represent four possible measures taken to estimate mean endocarp thickness. (C) Arrows represent three possible diameter measures used to check and record the largest diameter. 
supplementary material). For endocarps cut by macaws, only the half containing the germinative pore was measured.

The number of seeds per fruit ranged from one to five, and fruits harboring three seeds were the most frequent. Specifically, $11.6 \%$ were one seeded, $20.7 \%$ two-seeded, $45.8 \%$ three-seeded, $21.1 \%$ four-seeded and only two endocarps $(0.8 \%)$ were five-seeded (Fig. 2A). Such frequency distribution is similar to the one reported for acuri fruits collected beneath palm trees (Camilo-Alves \& Mourão 2010). Endocarp size distribution followed a normal distribution being $20.7 \mathrm{~mm}+2.7$ (mean $+\mathrm{SD})$.
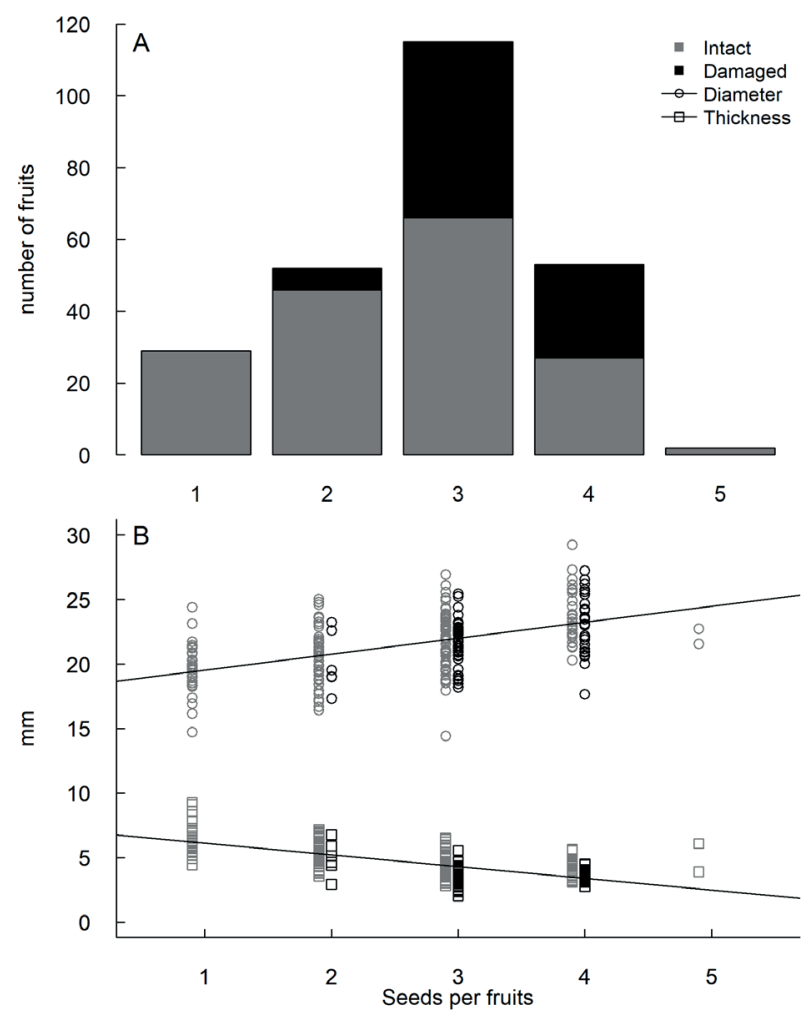

Figure 2. Traits of Attalea phalerata endocarps collected in tapir latrines at saline lakes at Fazenda do Rio Negro, Pantanal, Brazil. (A) Number of seeds in intact endocarps and in endocarps damaged by Anodorhynchus hyacinthinus macaws and (B) the larger fruit diameter and endocarp thickness for each fruit and its relation according to seed number.

Considering all fruits together (regardless of number of seeds), number of seeds was positively associated with fruit diameter $\left(\mathrm{F}=79.15 ; \mathrm{r}^{2}=0.24 ; \mathrm{p}<0.0001\right)$ and negatively associated with endocarp thickness $(\mathrm{F}=175.8 ; \mathrm{r} 2=0.42$; $\mathrm{p}<0.0001$; in both cases $\mathrm{n}=251$, Fig. 2B). Considering only fruits with the same number of seeds, the relationship between fruit size and diameter was still positive (Fig. 3; one seed: $F=12.06, R^{2}=0.28, n=29$; two seeds; $F=10.29$, $R^{2}=0.15: n=52$; three seeds: $F=20.50, R^{2}=0.15, n=115$; four seeds: $F=10.68, R^{2}=0.16, n=53$; all $\left.p<0.005\right)$. Although larger endocarps contain more seeds, the size distribution of endocarps with different seed numbers overlapped to some extent, especially between those with three or four seeds (Fig. 2B).

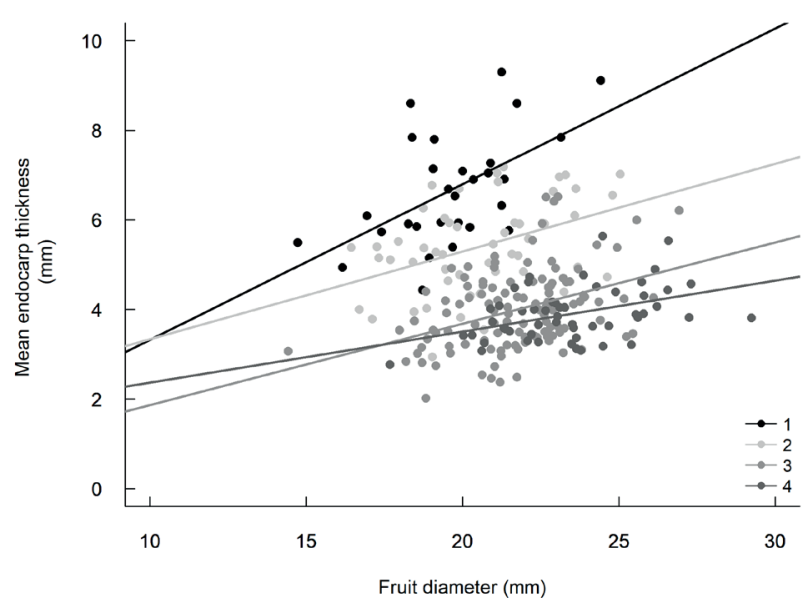

Figure 3. Relation between endocarp thickness and fruit diameter of Attalea phalerata fruits in each class of number of seeds per fruit.

To evaluate the potential effect of endocarp traits on fruit predation by macaws, we used generalized linear models (GLM) and subsequent model selection. Specifically, we tested whether presence/absence of predation was associated with fruit diameter and endocarp thickness. Our models assumed the response variable to follow a binomial error distribution, and considered both variables alone or in additive combinations. We also included an interceptonly (null) model as a benchmark for comparison. We assessed the plausibility of candidate models using Akaike's Information Criterion corrected for small samples (AICc, Burnham \& Anderson 2002). AICc values of each model were subtracted from the AICc value of the most plausible model $(\Delta \mathrm{i})$, and models were considered equally plausible if $\Delta \mathrm{i} \leq 2$ (Burnham \& Anderson 2002). All analyses were run in the $\mathrm{R}$ environment, version 3.4.0 ( $\mathrm{R}$ Development Core Team 2017). To run the GLM we used the package lme4 (Bates et al. 2015).

We found that $A$. phalerata seed predation by macaws was more frequent on fruits with larger diameters and thinner endocarps (Fig. S2). We found 251 fruits of $A$. phalerata in latrines, of which 170 were intact and 81 had been damaged by macaws. Out of the 81 fruits consumed by macaws, $7.4 \%$ had two seeds, $60.5 \%$ had three seeds and $32.1 \%$ had four seeds (Fig. 2).

The most plausible model indicated that fruits consumed by macaws tend to present specific traits, with thickness of the endocarp being more important than diameter (Tab. 1). Fruits harbouring three or four seeds suffered more predation than fruits with one, two or five seeds (Fig. 2A). Among three and four seeded fruits, predation was more frequent in fruit with thinner endocarps (Fig. 2B). Threeseeded fruits were the most abundant, but the fact that few two-seeded ones were predated, despite being as abundant as the four-seeded ones, indicates a potential preference for 
fruits with thinner endocarp and more seeds. This apparent preference likely results from a trade-off between the energy obtained from and expend to open the fruit, as the endocarp thickness decreases with the number of seeds and fruits with more seeds are likely easier to open.

Table 1. Model selection for Anodorhynchus hyacinthinus predation on Attalea phalerata fruits as a function of larger diameter (Diameter) and mean endocarp thickness (Endocarp). $\Delta_{\mathrm{i}}$ : difference of AICc value to the best model, $\omega_{\mathrm{i} \text { : }}$ Akaike weight, $\mathrm{K}$ : number of parameters. Plausible models are highlighted with bold letters.

\begin{tabular}{|c|c|c|c|}
\hline Diameter + Endocarp & $\Delta_{\mathbf{i}}$ & $\mathbf{K}$ & $\omega_{\mathbf{i}}$ \\
\hline Endocarp & $\mathbf{0}$ & $\mathbf{3}$ & $\mathbf{0 . 6 6}$ \\
\hline Diameter & $\mathbf{1 . 4}$ & $\mathbf{2}$ & $\mathbf{0 . 3 4}$ \\
\hline constant & 85.4 & 2 & $<0.001$ \\
\hline & 86.4 & 1 & $<0.001$ \\
\hline
\end{tabular}

In fact, macaws seem to select certain acuri fruits based on their traits. Although macaws could act as selective agents favouring trees that produce more fruits with one and two seeds, in the Pantanal ecosystem, this force may be counterbalancing acuri seed predation by bruchids (Bradford \& Smith 1977; Ragusa-Netto 2019) and small rodents (Camilo-Alves \& Mourão 2010) that are highly effective predators of single-seeded fruits which, by its turn, favours multi-seeded fruits. As macaws, rodents and bruchids can co-occur with acuri populations and impose opposite selection forces, they may contribute to maintain the variability in the number of seeds per fruit in A. phalerata populations. Furthermore, differences on how each of these predator species opens the endocarp and consume seeds may be important. On the one hand, macaws cut fruits in half, making unfeasible the germination of any seed from the fruit and, over evolutionary time, it would be expected that the preferred fruits will no longer be available in the acuri population. On the other hand, rodents make holes in the endocarps to access the endosperm, consuming just one or two of them and often leaving some of the seeds intact. As a consequence, the survival of seeds in multiple seeded fruits attacked by rodents is higher than in the single-seeded fruits, and the remaining seeds can germinate (Camilo-Alves \& Mourão 2010). Thus, rodents act as seed dispersers and help to maintain the multi-seeded trait in the acuri population, possibly benefiting macaws, which show preference for multi-seeded fruits but do not leave any seed with this genotype for germination.

Here we show that most acuri fruits predated by macaws on tapir latrines usually have 3 or 4 seeds. The effect of macaws in the reproductive success of acuri palms is part of a complex ecological scenario including opposite seed predation forces played by macaws, bruchids and small rodents, which contributes to maintaining the genetic diversity of acuri palm populations. Nonetheless, there is still much to learn on the role of each player in the selection of seed numbers in Attalea fruits to understand the mechanism underlying the maintenance of such traits within the population. Advances in this direction may derive from studies investigating spatial and temporal variations in both palm and seed predator populations.

\section{Acknowledgements}

This study was carried out during the Ecology and Conservation Course of Universidade Federal de Mato Grosso do Sul at Fazenda Rio Negro that provides all logistical support. We are indebted to the two anonymous reviewers for the careful review of the manuscript and for the suggestions that have improved it considerably. Fernando Fernandez and Rita Portela also provide critical review and suggestions. CSB had postdoctoral scholarships from CAPES- Finance Code 001 and ASP from CNPq (PQ309505/2015-1).

\section{References}

Bates D, Maechler M, Bolker B, Walker S. 2015. Fitting Linear MixedEffects Models Using lme4. Journal of Statistical Software 67: 1-48. Bradford DF, Smith CC. 1977. Seed predation and seed number in Scheelea palm fruits. Ecology 58: 667-673.

Brandt A, Machado RB. 1990. Área de alimentação e comportamento alimentar de Anodorhyncus leari (Feeding sites and feeding behaviour of Anodorhyncus leari). Ararajuba 1: 57-63.

Burnham KP, Anderson DR. 2002. Model selection and multimode inference: A practical Information- Theoretic Approach. 2nd. edn. Colorado, Springer.

Camilo-Alves CSP, Mourão GM. 2010. Palms use a bluffing strategy to avoid seed predation by rats in Brazil. Biotropica 42: 167-173.

Capace PI, Alioga-Rossel E, Janzen PA. 2013. Viability of small seeds in feces of the Central American tapir on Barro Colorado Island, Panama. Integrative Zoology 8: 57-62.

Dracxler CM, Forget PM. 2017. Seed catching by rodents favours seedling establishment of two palm species in a lowland Atlantic Forest remnant. Journal of Tropical Ecology 33: 228-231.

Fragoso JMV. 1997. Tapir-generated seed shadows: Scale-dependent patchiness in the Amazon rain forest. Journal of Ecology 85: 519-529

Fragoso JMV, Silvius KM, Correa JA. 2003. Long-distance seed dispersal by tapirs increases seed survival and aggregates tropical trees. Ecology 84: 1998-2006

Galeano G, Bernal R, Hederson A. 1995. Field guide to the palms of the Americas. Princeton, Princeton University Press.

Galetti M, Guimarães Jr. PR. 2004. Seed dispersal of Attalea phalerata (Palmae) by Crested caracaras (Caracara plancus) in the Pantanal and a review of frugivory by raptors. Ararajuba 12: 133-135.

Guedes NMR, Harper LH. 1995. Hyacinth macaws in the Pantanal: conservation and management. In: Abramson J, Speer BL, Thomsen JB. (eds.) The Large Macaws: their care, breeding and conservation. California, Raintree Publications. p. 394-421.

Jordano P. 1995. Frugivore-mediated selection on fruit and seed size: birds and St. Lucie's Cherry, Prunus mahaleb. Ecology 76: 2627-2639.

Machado RB, Silva SM, Pinto ECT, Camargo G, Ribeiro AP. 2009. Plano de manejo da Reserva Particular do Patrimônio Natural Fazenda Rio Negro. Rio de Janeiro, Serviço Social do Comércio - SESC. https:// www.researchgate.net/profile/Paulo-Antas-2/publication/267267555_ Plano_de_Manejo_da_Reserva_Particular_de_Patrimonio_ 
Natural_do_SESC_Pantanal_2_edicao_-revista_e_atualizada/ links/544908970cf2ea6541301860/Plano-de-Manejo-da-ReservaParticular-de-Patrimonio-Natural-do-SESC-Pantanal-2-edicao-revistae-atualizada.pdf.

Pires MM, Galetti M, Donatti C, Pizo MA, Dirzo R, Guimarães Jr PR. 2014. Reconstructing past ecological networks: the reconfiguration of seed-dispersal interactions after megafaunal extinction. Oecologia 175: 1247-1256

Quiroga-Castro VD, Roldán AI. 2001. The fate of Attalea phalerata (Palmae) seeds dispersed to a tapir latrine. Biotropica 33: 472-477.

R Development Core Team. 2017. R: A language and environment for statistical computing. R foundation for Statistical Computing. Vienna, Austria. https://R-project.org/. 17 March 2017.
Ragusa-Netto J. 2019. Density-dependent seed predation in Attalea geraensis Barb. Rodr. (Arecaceae) caused by bruchid beetles in the Brazilian Cerrado. Brazilian Journal of Biology 79: 577-583.

Tobler MW, Janovec JP, Cornejo F. 2010. Frugivory and seed dispersal by the lowland Tapir -in the Peruvian Amazon. Biotropica 42: 215-222.

Yamashita C. 1987. Field observations and comments on the indigo macaw Anodorhynchus leari, a highly endangered species from northeastern Brazil. Wilson Bulletin 99: 280-282.

Yamashita C. 1997. Anodorhynchus macaws as followers of extinct megafauna: an hypothesis. Ararajuba 5: 176-182.

Yamashita C, Valle MP. 1993. The linkage between Anodorhynchus macaws and the palm nuts and the extinction of the glaucous macaw. Bulletin of the British Ornithologists' Club. 113: 53-60. 